\title{
Aqueous-phase oligomerization of methyl vinyl ketone through photooxidation - Part 1: Aging processes of oligomers
}

\section{P. Renard et al.}

Correspondence to: P. Renard (pascal.renard@etu.univ-amu.fr) 


\section{$\underline{\text { Supplementary Information }}$}

\section{Supplementary Information 1: Calibration experiments of our set up}

Calibration experiments of our set up were performed using aqueous solutions of three different compounds ( $\mathrm{NaCl}, \mathrm{NH}_{4} \mathrm{NO}_{3}$, and succinic acid) at various concentrations covering those of the consumed MVK during its reaction (Table S1). In these calibration experiments, for each compound, the obtained numbers of particles increase with increasing solution concentrations, and the corresponding total particle mass (using the corresponding densities) increases linearly with the solution concentration. This result was used to evaluate the transmission efficiency of our set up. Assuming a similar behavior for the nebulized MVK-oligomers up to $t_{\max }$ (i.e. increasing oligomer concentrations with reaction time, assuming no major change in the oligomer composition), the calibration experiments were used to determine the SOA mass yields according to equations 2 and 3. The differences obtained between the three calibration experiments may be due to the different physical properties of the particles (e.g. volatility, surface tension and hygroscopicity) linked to their chemical composition. Table S1 shows that the solutions of $\mathrm{NaCl}$ generated a significantly higher transmission efficiency than the solutions of $\mathrm{NH}_{4} \mathrm{NO}_{3}$ and succinic acid. It is likely that the properties of the SOA generated from the nebulized solutions of oxidized MVK were closer to that of $\mathrm{NH}_{4} \mathrm{NO}_{3}$ and succinic acid than $\mathrm{NaCl}$. Finally, the transmission efficiency obtained for $\mathrm{NH}_{4} \mathrm{NO}_{3}$ solutions was used to calculate the SOA mass yields according to equations 2 and 3.

\begin{tabular}{lllll}
\hline Compound & $\begin{array}{l}\text { Range of aqueous phase } \\
\text { concentration } \\
\left(\mathrm{mg} \mathrm{L}^{-1}\right)\end{array}$ & $\begin{array}{l}\text { Range of particle mass } \\
\text { concentration after nebulization } \\
\left(\mu \mathrm{g} \mathrm{m}^{-3}\right)\end{array}$ & $\begin{array}{l}\text { Particle density } \\
\left(\mathrm{g} \mathrm{cm}^{-3}\right)\end{array}$ & $\begin{array}{l}\text { Transmission } \\
\text { efficiency }(\%)\end{array}$ \\
\hline Succinic acid & $50-2000$ & $20-1300$ & 1.56 & $13.1( \pm 2.6)$ \\
$\mathrm{NH}_{4} \mathrm{NO}_{3}$ & $30-3000$ & $10-4500$ & 1.73 & $17.2( \pm 7.9)$ \\
$\mathrm{NaCl}$ & $50-2000$ & $100-4000$ & 2.17 & $44.6( \pm 2.3)$ \\
\hline
\end{tabular}

Table S1: Determination of particle transmission efficiency in the particle generation system 
Supplementary Information 2: Average spectral irradiance of the Xe lamps

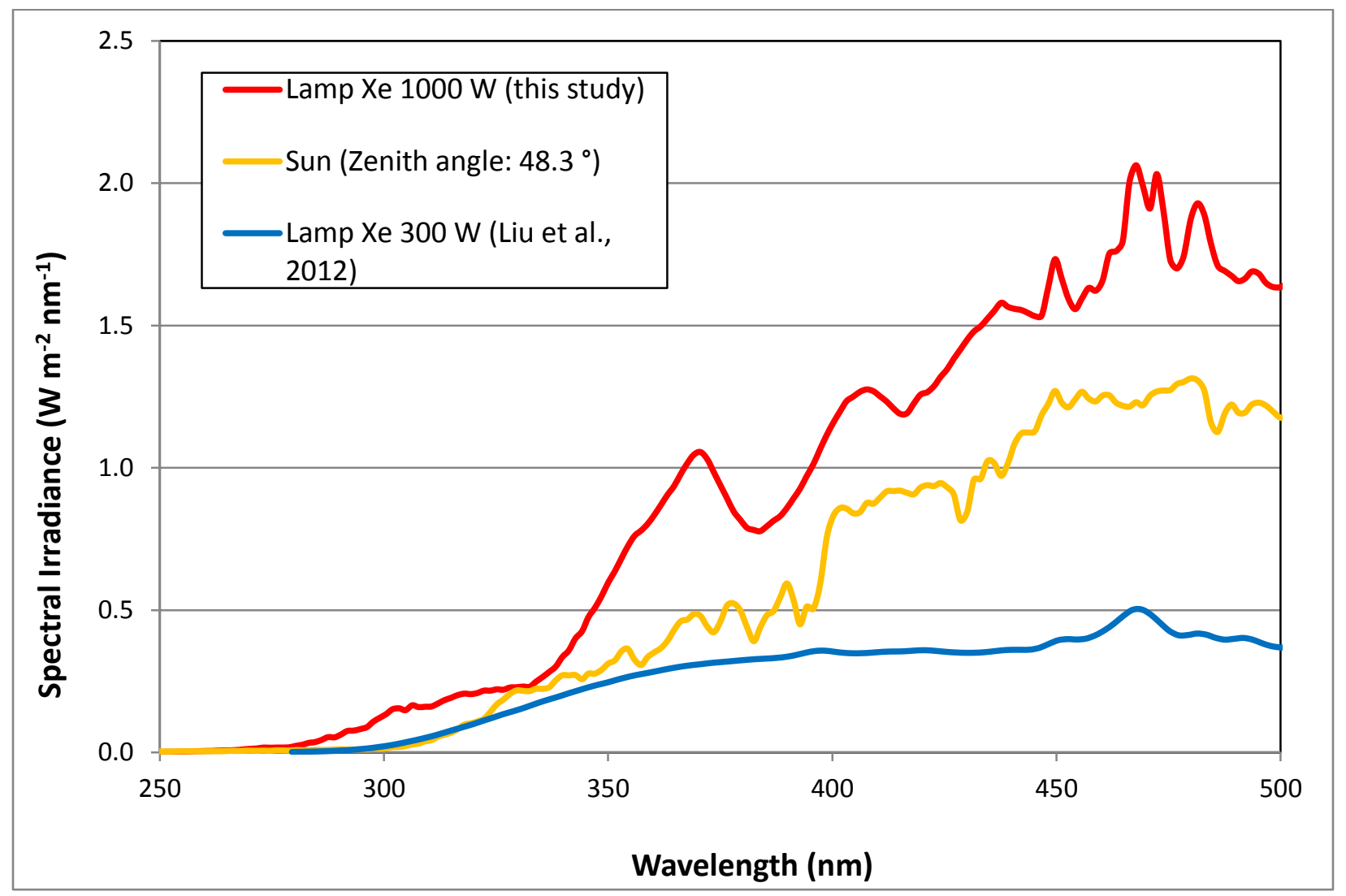

Figure S1: Figure S1: Average spectral irradiance of the Xe lamps $1000 \mathrm{~W}$ with a ASTM 490 AM 0 filter (in red, used in the present study), $300 \mathrm{~W}$ with a pyrex filter (in blue, Liu et al., 2012), and as compared to the direct solar irradiance at sea level, for a $48.3^{\circ}$ zenith angle (in orange). 


\section{Supplementary Information 3: Determination of ${ }^{\circ} \mathrm{OH}$ concentrations in the solution}

${ }^{\circ} \mathrm{OH}$ concentrations were calculated by means of two different methods (methods a) and b) below), which gave similar results:

a) Considering reactions $\mathrm{R} 1$ to $\mathrm{R} 3{ }^{\circ} \mathrm{OH}$ concentrations were calculated assuming the steady state approximation at time 0 :

$$
[\mathrm{OH}]=\frac{2 \times J_{H 2 O 2} \times[H 2 O 2]}{k_{3} \times[M V K]+k_{2} \times[H 2 O 2]}
$$

$\mathrm{H}_{2} \mathrm{O}_{2}+\mathrm{h} v \stackrel{\mathrm{J}_{\mathrm{H} 202}}{\longrightarrow} 2^{\circ} \mathrm{OH}$

$\mathrm{J}_{\mathrm{H} 2 \mathrm{O} 2}$ was determined by fitting $\mathrm{H}_{2} \mathrm{O}_{2}$ concentration decay

$\mathrm{H}_{2} \mathrm{O}_{2}+{ }^{\circ} \mathrm{OH} \stackrel{k_{2}}{\rightarrow} \mathrm{HO}_{2}^{\cdot}+\mathrm{H}_{2} \mathrm{O}$

$\mathrm{k}_{2}=2.95 .10^{7} \mathrm{M}^{-1} \mathrm{~s}^{-1}$ at $25^{\circ} \mathrm{C}$

(Christensen et al., 1982)

$\mathrm{MVK}+{ }^{\circ} \mathrm{OH} \stackrel{k_{\mathrm{MVK}}}{\longrightarrow}$ Products

$\mathrm{k}_{3}=7 \cdot 3 .( \pm 0,5) 10^{9} \mathrm{M}^{-1} \mathrm{~s}^{-1}$ at $25^{\circ} \mathrm{C} \quad$ (Schöne et al., 2014)

The obtained values are $\left[{ }^{\circ} \mathrm{OH}\right]=(6-5) \times 10^{-14} \mathrm{M}$ (for $\mathrm{pH} 6-3$ respectively)

b) Fitting the initial MVK decay with an exponential decay:

$$
[M V K]_{t}=[M V K]_{0} \times e^{-\left(-\mathrm{k}_{3} \times\left[{ }^{*} \mathrm{OH}\right] \times \mathrm{t}\right)}
$$

With $\mathrm{k}_{3}=7,3 .( \pm 0,5) 10^{9} \mathrm{M}^{-1} \mathrm{~s}^{-1}$ at $25^{\circ} \mathrm{C}$ (Schöne et al., 2014), we obtained similar values for ${ }^{\circ} \mathrm{OH}$ steady state concentrations $\left(\left[{ }^{\circ} \mathrm{OH}\right]=2 \times 10^{-14} \mathrm{M}\right)$ as for method a). 


\section{References}

Christensen, H., Sehested, K. and Corfitzen, H.: Reactions of hydroxyl radicals with hydrogen peroxide at ambient and elevated temperatures, J. Phys. Chem., 86(9), 1588-1590, doi:10.1021/j100206a023, 1982.

Liu, Y., Siekmann, F., Renard, P., El Zein, A., Salque, G., El Haddad, I., Temime-Roussel, B., Voisin, D., Thissen, R. and Monod, A.: Oligomer and SOA formation through aqueous phase photooxidation of methacrolein and methyl vinyl ketone, Atmospheric Environment, 49, 123129, doi:10.1016/j.atmosenv.2011.12.012, 2012.

Schöne, L., Schindelka, J., Szeremeta, E., Schaefer, T., Hoffmann, D., Rudzinski, K. J., Szmigielski, R. and Herrmann, H.: Atmospheric aqueous phase radical chemistry of the isoprene oxidation products methacrolein, methyl vinyl ketone, methacrylic acid and acrylic acid - kinetics and product studies, Physical Chemistry Chemical Physics, 16(13), 6257, doi:10.1039/c3cp54859g, 2014. 